\title{
Animais como modelos experimentais nos cursos de graduação na área da saúde: revisão sistemática
}

\author{
Animals as experimental models in undergraduate health courses: systematic review \\ Los animales como modelos experimentales en cursos de pregrado en salud: revisión \\ sistemática
}

\begin{abstract}
Benedito Pereira de Sousa Neto ${ }^{1}$, Nilton Andrade Magalhães ${ }^{1}$, Layane Valeria Amorim ${ }^{1}$, Luciana Stanford Baldoino ${ }^{1 *}$, Tatiana Naiana Rodrigues dos Santos Porto ${ }^{1}$, Vinícius de Sousa Martins ${ }^{1}$, Dorivaldo Pereira Carvalho', Rita de Cássia Rêgo de Araújo¹, Sônia Maria Leite Alcântara¹.
\end{abstract}

\section{RESUMO}

Objetivo: Discutir com base em artigos científicos a substituição de animais por recursos tecnológicos em ensaios experimentais no ensino superior na área de saúde e sua evolução no Brasil. Métodos: Realizou-se revisão sistemática nas bases: National Library of Medicine National Institutes of Health dos EUA (PUBMED), Medical Literature Analysis and Retrieval System Online (MEDLINE), Literatura Latino-Americana e do Caribe em Ciências da Saúde (LILACS), e Scientific Eletronic Library Online (SCIELO), utilizando os descritores: "bioética," "bem-estar animal" "ética em pesquisa", "experimentação animal". Foram selecionados 7 artigos publicados em português e inglês no período de 2000 a 2017. Resultados: Nos últimos anos tem-se discutido muito a utilização de animais em pesquisas e no ensino superior. É uma prática antiga, ainda fere a sensibilidade humana, e provoca discussões entre estudantes, professores e a sociedade, que vão além da barreira ética, pois, muitos questionam a real eficácia dessa metodologia de ensino diante dos avanços tecnológico-científicodisponível atualmente. Considerações Finais: Nesse cenário surgem alternativas que substituem o uso de animais em ensaios experimentais por programas de computadores, softwares ou manequim que mimetizam parâmetros fisiológicos. Evidenciou-se que a utilização de animais como modelo experimental está passando por processo de transformação tanto nos aspectos legais como metodológicos.

Palavras-chave: Alternativas aos testes com animais, Animais de laboratório, Bioética, Métodos alternativos para pesquisa.

\section{ABSTRACT}

Objective: To discuss based on scientific articles the replacement of animals by technological resources in experimental tests in higher education in the area of health and its evolution in Brazil. Methods: A systematic review of the databases was performed: National Library of Medicine National Institutes of Health (PUBMED), Medical Literature Analysis and Retrieval System Online (MEDLINE), Latin American and Caribbean Literature in Health Sciences (LILACS), and Scientific Electronic Library Online (SCIELO), using the descriptors: "bioethics," "animal welfare" "research ethics", "animal experimentation". 7 articles published in Portuguese and English from 2000 to 2017 were selected. Results: In recent years there has been much discussion on the use of animals in research and higher education. It is an old practice, still hurts human sensibility, and provokes discussions among students, teachers, and society, which go beyond the ethical barrier, because many question the real effectiveness of this teaching methodology in the face of technological and scientific

\footnotetext{
${ }^{1}$ Faculdade de Ensino Superior Múltiplo - IESM, Timon - MA.

*E-mail: Isbaldoino@hotmail.com.br
} 
advances available today. Final Considerations: In this scenario, alternatives arise that replace the use of animals in experimental trials with computer programs, software or mannequins that mimic physiological parameters. It has been shown that the use of animals as an experimental model is undergoing a process of transformation in both legal and methodological aspects.

Keywords: Alternatives to animal testing, Laboratory animals, Bioethics, Alternative methods for research.

\section{RESUMEN}

Objetivo: Discutir con base en artículos científicos la sustitución de animales por recursos tecnológicos en pruebas experimentales en la educación superior en el área de la salud y su evolución en Brasil. Métodos: Se realizó un examen sistemático de las bases de datos: Biblioteca Nacional de Medicina Institutos Nacionales de Salud (PUBMED), Sistema de Análisis y Recuperación de Literatura Médica en Línea (MEDLINE), Literatura Latinoamericana y del Caribe en Ciencias de la Salud (LILACS) y Biblioteca Científica Electrónica en Línea (SCIELO), utilizando los descriptores: "bioética", "bienestar animal", "ética de la investigación", "experimentación animal". Se seleccionaron 7 artículos publicados en portugués e inglés de 2000 a 2017. Resultados: En los últimos años se ha discutido mucho sobre el uso de animales en la investigación y la educación superior. Es una práctica antigua, que todavía hiere la sensibilidad humana y provoca discusiones entre los estudiantes, los profesores y la sociedad, que van más allá de la barrera ética, porque muchos cuestionan la eficacia real de esta metodología de enseñanza frente a los avances tecnológicos y científicos disponibles hoy en día. Consideraciones finales: En este escenario, surgen alternativas que sustituyen el uso de animales en los ensayos experimentales por programas informáticos, software o maniquíes que imitan los parámetros fisiológicos. Se ha demostrado que la utilización de animales como modelo experimental está experimentando un proceso de transformación tanto en los aspectos jurídicos como metodológicos.

Palabras clave: Alternativas a los ensayos con animales, Animales de laboratorio, Bioética, Métodos alternativos de investigación.

\section{INTRODUÇÃO}

No século XVII, o filósofo René Descartes, formulou a teoria mecanicista, segundo a qual o animal era um ser desprovido de espírito, logo, não poderia sentir dor, isso corroborava com teorias anteriores, que já afirmava a superioridade da espécie humana e tornando os demais animais uma simples máquina (SILVA TTA, et al., 2010). A utilização de animais como modelos experimentais em pesquisa pode ser compreendida como um processo que visa favorecer o conhecimento científico. Embora seja uma técnica relativamente antiga, ainda hoje esse procedimento fere a sensibilidade humana fato que vem provocando discussões entre estudantes e a sociedade protetora dos animais (SCHATZMAYR IR, et al., 2008).

No entanto, essas discussões vão além da barreira ética, pois muitos estudiosos questionam a real eficácia de métodos antigos de ensino diante dos avanços tecnológico-científico disponível (MORALES MN, et al., 2008 e RODRIGUES GS, et al., 2011).

Vale destacar que os defensores dos direitos dos animais acreditam que a utilização destes pode ser substituída por recursos tecnológicos, argumentando ainda que a utilização dos mesmos não garante reprodutibilidade em outra espécie, principalmente nos humanos (MAGALHES MM, et al., 2008 e RODRIGUES GS, et al., 2011).

Um fato que reforça essa teoria é o caso da talidomida, que apresentou alta teratogenicidade em humanos, porém, não foi observado em testes em roedores (CHUNG F, et al., 2004).Tendo em vista, por maior que seja a complexidade do tema, vários centros universitários ainda utilizam animais como modelos experimentais em busca da cura ou tratamento para diversas doenças, testes farmacológicos, justificando a necessidade de monitoração dos efeitos observados em estudos clínicos.

Dessa forma, surgiu a necessidade de regulamentar a utilização de animais em pesquisas no Brasil, buscando assim, evitar procedimentos que proporcione maus-tratos aos animais submetidos a técnicas 
experimentais (MARQUES RG, et al., 2005 e REZENDE AH, et al., 2008). A prática com animais em experimento, remota ao período em que não existia clareza entre religião e ciência. Com o aparecimento da tradição judaico-cristã, a partir do século $\mathrm{V}$, favoreceu ainda mais essa prática, principalmente influenciada pela ideia que tais seres são desprovidos de alma (TINOCO IAP, et al., 2010).

No período renascentista, onde se tem o homem como personagem central, e que os outros seres existentes deveriam servi-lo, intensificou-se ainda mais o uso de animais em ensaios experimentais (TINOCO IAP, et al., 2010). Já na segunda metade do século XIX o filósofo Jeremy Bentham, deu início à base para a legislação que defende o direito dos animais na atualidade (MENEZES HS, et al., 2002). Em seu trabalho discutia até que ponto era verdade a ausência do sofrimento animal. Para ele existia diferença obvia entre a capacidade de pensar e a capacidade de sofrer (MENEZES HS, et al., 2002).

Ainda no século XIX, foram criadas na Inglaterra a lei Britânica Anticrueldade (British Anticruelty Act) que visava diminuir atos de crueldade envolvendo animais, no entanto, só exercia jurisdição para animais domésticos de grande porte; Sociedade para a Prevenção da Crueldade Animal (Society for the Prevention of Cruelty to Animals), a qual serviu de modelo para a criação de outras entidades semelhantes principalmente na Europa. Somente em 1876 que a Inglaterra cria a primeira lei que regulamentava o uso de animais em experimentos (MENEZES HS, et al., 2002).

É pertinente mencionar que um pesquisador importante nesse contexto foi Charles Darwin, no século XIX, sem dúvidas esse impulsionou a pesquisa científica em todo mundo, a partir do momento da publicação de seu trabalho, "A origem das espécies". Dessa forma, o autor afirma que, as espécies de animais existentes no planeta são produtos de evolução.

Esse fato pode ter favorecido testes em outros animais que mimetizasse a situação em seres humanos (GUIMARÃES MV, et al., 2016). A tendência mundial é a substituição do uso de animais em ensino de graduação, principalmente na área da saúde. Em países desenvolvidos como Canadá, Estados Unidos, Itália e Alemanha, não utilizam mais animais em práticas laboratoriais. Nesses países em se tratando de ensino, os animais são substituídos sem prejuízos, devido aos altos recursos tecnológicos disponíveis nos centros universitários (DINIZ R, et al., 2006).

Existem várias alternativas para realização de aulas práticas que mimetizam os sistemas biológicos. Testes in vitro como cromatografia e espectrometria de massa; farmacologia e mecânica quântica; estudos epistemológicos; estudos clínicos; necropsias e biopsias; simulações computadorizadas; modelos matemáticos; culturas de bactérias e protozoários são os testes mais usuais (LEVAI LFO, et al., 2010).

Nos Estados Unidos e Europa esses métodos alternativos aboliram o uso de animais no ensino. A educação atualizada e sincronizada com métodos alternativos envolto no progresso tecnológico contribui para o pensamento ético dos alunos e propicia um ambiente saudável de aprendizagem com o mínimo de conflitos éticos envolvendo o contexto educacional (PRESGRAVE OAF, et al., 2010). Vale enfocar que o uso de animais como modelos experimentais em pesquisas é marcado por dualidades.

De um lado têm-se pesquisadores defendendo a importância e a necessidade de práticas in vivo, do outro, defensores dos animais que expressam o desejo de abolir por completo o seu uso em aulas ou práticas experimentais (HAGELIN J, et al., 2003). Knight S, et al. (2009), afirmam que os argumentos utilizados pelos opositores ou apoiadores da pesquisa com uso de animais pouco mudaram ao longo do tempo. Basicamente, os que discordam tendem a defender o princípio do bem-estar animal, destacando o sofrimento dos mesmos e os que apoiam defendem a importância do seu trabalho para a população e a ausência de alternativa onde pudessem reproduzir seus resultados os mais próximos dos seres humanos. Dessa forma, pode se presumir que cada organismo possui maquinaria enzimática específica para determina substância.

Mesmo sabendo dessa incompatibilidade enzimática, a maiorias dos centros de pesquisas utilizam os modelos clássicos com animais em seus ensaios experimentais, objetivando com os mesmo a descoberta de curas ou entender determinados mecanismos de ação farmacológica ou ainda avaliar os seus possíveis efeitos colaterais (MARQUES RG, et al., 2005). 
Entretanto, a utilização de animais no meio acadêmico como modelos experimentais está basicamente voltada para ensino, pesquisa e teste de produtos ou ainda para treinamento de alunos na área biomédica. No entanto, alguns autores discordam dessas metodologias de aprendizagem, afirmando ser ilegal, imoral e ainda não reproduz de forma fiel a fisiologia humana. Nessa perspectiva sugerem o uso de técnicas alternativas como, por exemplo, testes in vitro, outra sugestão seria a utilização de seres humanos voluntários em práticas não invasivas, testes físico-químicos e estudos em cadáveres.

Outros recursos seriam programas de computadores, softwares educacionais, modelos matemáticos, filmes, nanotecnologia e manequins que reproduzem com bastante fidelidade os testes in vivo (GREIF S, et al., 2000; GREIF S, et al., 2003). Assim a problemática do estudo aborda a seguinte hipótese: até que ponto é viável a substituição de animais como modelos experimentais por programas de computadores que simulem as condições reais de um ser humano?

Contudo, a substituição de animais em aulas práticas é uma tendência mundial, visto isso, o presente trabalho tem como objetivo discutir com base em artigos científicos a substituição de animais por recursos tecnológicos em ensaios experimentais no ensino superior na área de saúde e sua evolução no Brasil.

\section{MÉTODOS}

Nesse estudo, realizou-se uma revisão sistemática sobre o assunto em questão, por meio de consulta nas bases de dados PubMed da National Library of Medicine National Institutes of Health dos EUA (PUBMED),Medical Literature Analysis and Retrieval System Online (MEDLINE), Literatura Latino-Americana e do Caribe em Ciências da Saúde (LILACS), e Scientific Eletronic Library Online (SCIELO), utilizando os seguintes descritores: "bioética," "bem-estar animal" "ética em pesquisa", "experimentação animal," além das expressões equivalentes em inglês. Para inclusão e análise dos artigos, foram inseridos artigos publicados na língua portuguesa e inglesa no período de 2005 a 2017 e como critérios de exclusão, os artigos que não se incluíam no intervalo de tempo da pesquisa e que abordavam questões que fugiam do tema.

Após a aplicação dos critérios de exclusão e de inclusão, foram selecionados 7 artigos os quais foram lidos na íntegra com o objetivo de sumarizar e ordenar os dados contidos neles, buscando obtenção de resposta ao problema da pesquisa (Figura 1). 
Figura 1 - Fluxograma da aplicação das etapas dos critérios de inclusão e exclusão dos artigos para amostra final. Timon- MA, 2020.

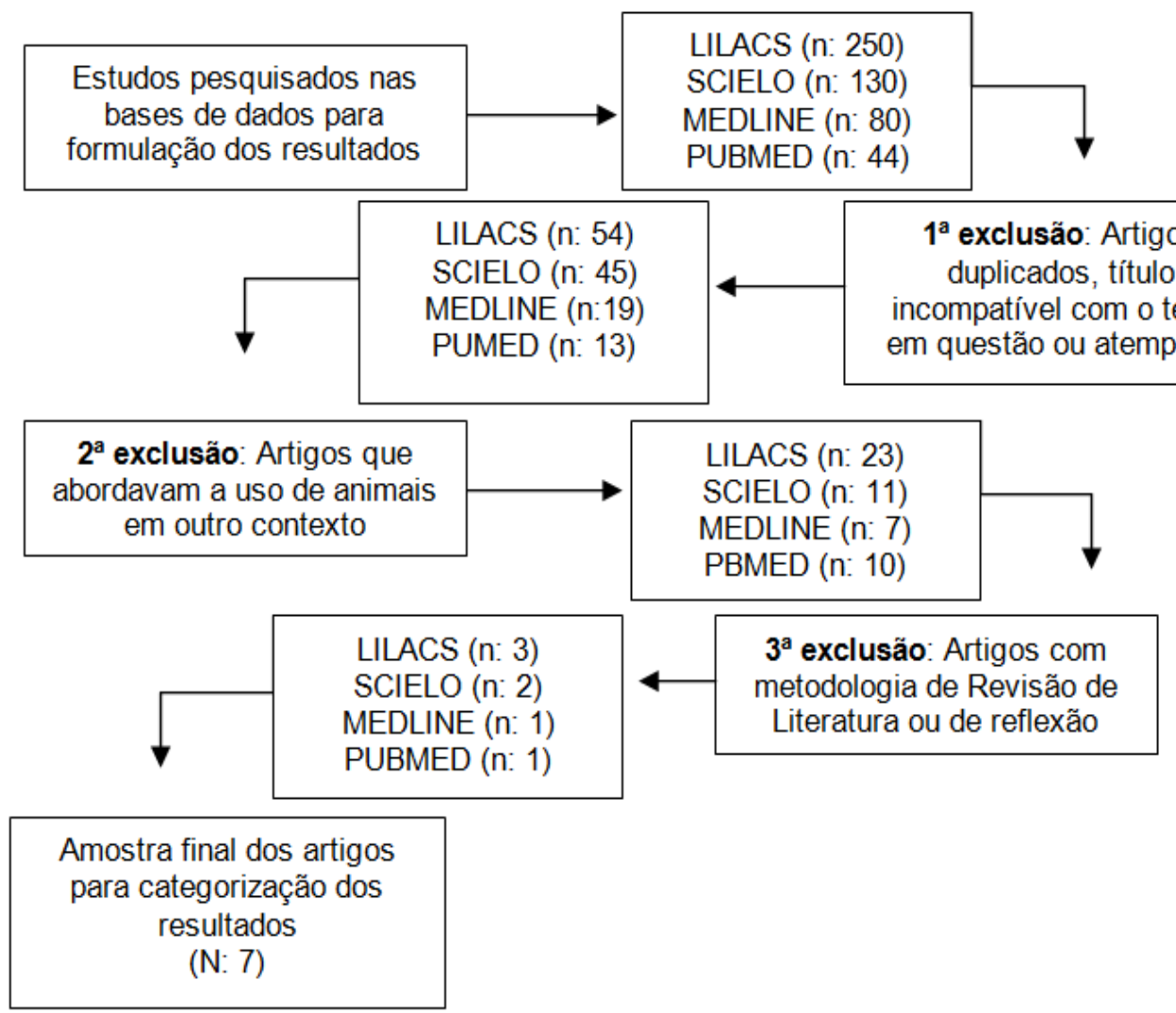

Fonte: Porto TNRS, et al., 2020.

\section{RESULTADOS E DISCUSSÃO}

Os dados encontrados foram evidenciados em quadro com a caracterização, refletindo a síntese das características dos estudos incluídos. Posteriormente seguiu-se a análise e a discussão dos resultados fundamentada no diálogo dos autores que discutem a temática (Quadro 1) 
Quadro 1 - Caracterização dos estudos incluídos, segundo informações como: Ano de publicação, Objetivo e principais resultados. Timon (MA), Brasil, 2020.

\begin{tabular}{|c|c|c|c|}
\hline AUTOR (ES) & $\begin{array}{c}\text { ANO DE } \\
\text { PUBLICAÇÃO }\end{array}$ & OBJETIVO & PRINCIPAIS RESULTADOS \\
\hline YUNTA ER, et al. & 2007 & $\begin{array}{l}\text { Discutir as implicações éticas do uso de animais como } \\
\text { modelos para o desenvolvimento da medicina humana. }\end{array}$ & $\begin{array}{l}\text { Que é mais razoável adotar a posição intermediária de } \\
\text { considerar o uso de animais de pesquisa como } \\
\text { necessário para se ajustar ao imperativo moral de curar e } \\
\text { prevenir doenças humanas, mas procurando maneiras de } \\
\text { substituir e reduzir seu número e diminuir seu sofrimento. }\end{array}$ \\
\hline SHELLEY CW. & 2010 & $\begin{array}{c}\text { Estabelecer que a modelagem animal é inútil e, } \\
\text { portanto, imoral, utilizando-se de argumentos críticos, } \\
\text { dos quais estes são divididos em três tipos: } \mathrm{O} \\
\text { argumento da pseudociência, } \\
\text { o argumento da desanalogia e o argumento da validade } \\
\text { preditiva. }\end{array}$ & $\begin{array}{l}\text { Pelo menos até agora, nenhum desses argumentos } \\
\text { críticos conseguem argumentando que o modelo animal é } \\
\text { necessariamente ou semprenão válido. }\end{array}$ \\
\hline FRANCO AL, et al. & 2014 & $\begin{array}{l}\text { Levantar e apresentar as normas atuais que } \\
\text { regulamentam as pesquisas em animais no Brasil } \\
\text { comparando-as a outros países, bem como fomentar } \\
\text { reflexões bioéticas sobre esse mote. }\end{array}$ & $\begin{array}{l}\text { É evidente a contribuição dos animais para pesquisas } \\
\text { científicas de diversas áreas. Cabe moralmente ao } \\
\text { Homem, como ser racional, garantir um tratamento digno } \\
\text { aos animais que contribuem para a pesquisa. A forma } \\
\text { mais segura de seguir este caminho é estabelecendo leis } \\
\text { claras e pesquisas bem delineadas, que envolvam a } \\
\text { sociedade para designar normas éticas. Dessa forma, o } \\
\text { bem-estar animal estaria garantido. }\end{array}$ \\
\hline FISCHER ML, et al. & 2016 & $\begin{array}{l}\text { Caracterizar a concepção de estudantes universitários } \\
\text { sobre o uso de animais a fim de fornecer subsídios para } \\
\text { programas de educação ambiental. }\end{array}$ & $\begin{array}{c}\text { O resultado conduz a uma interpretação importante de } \\
\text { que a falta de informação e conscientização parecem ser } \\
\text { componentes essenciais para mudança nas atitudes } \\
\text { éticas. }\end{array}$ \\
\hline
\end{tabular}




\begin{tabular}{|c|c|c|c|}
\hline PINHEIRO LM, et al. & 2007 & $\begin{array}{l}\text { Levantar dados sobre a questão } \\
\text { da utilização de recursos } \\
\text { alternativos em substituição aos } \\
\text { animais de laboratório, bem } \\
\text { como averiguar o nível de } \\
\text { conhecimento e a possibilidade } \\
\text { de utilização desses meios por } \\
\text { parte de professores, alunos e } \\
\text { pesquisadores da Pontifícia } \\
\text { Universidade Católica do } \\
\text { Paraná. }\end{array}$ & $\begin{array}{l}\text { Constatou-se que apenas } 40 \% \text { dos entrevistados possuem conhecimento } \\
\text { sobre recursos alternativos. Observou-se ainda que } 53 \% \text { dos } \\
\text { entrevistados veem a possibilidade do uso desses recursos em seus } \\
\text { experimentos. Entre os pesquisadores que já utilizaram ou utilizam os } \\
\text { recursos alternativos, } 67 \% \text { considera os resultados obtidos adequados } \\
\text { em comparação aos experimentos realizados com cobaias animais. }\end{array}$ \\
\hline 4OLIVEIRA FCS, et al. & 2009 & $\begin{array}{c}\text { A análise da experimentação } \\
\text { científica com animais não- } \\
\text { humanos. }\end{array}$ & $\begin{array}{l}\text { No que diz com a normatividade, crucial, incontornável, a disposição } \\
\text { constitucional que impede que os animais sejam submetidos à crueldade } \\
\text { (art. 225, § 1º, VII). Todo ser vivo, independente de pertencente à espécie } \\
\text { humana, é detentor de dignidade (dignidade humana e não-humana - } \\
\text { dignidade animal), possui valor em si mesmo, deve ser reconhecido como } \\
\text { sujeito e não como objeto, é digno de compaixão, respeito e amor. }\end{array}$ \\
\hline MARQUES RG, et al. & 2005 & $\begin{array}{l}\text { Relatar a evolução na } \\
\text { regulamentação brasileira sobre } \\
\text { o uso científico de animais e } \\
\text { analisar a Lei n.․ } 11.794\end{array}$ & $\begin{array}{l}\text { A partir do clamor e da colaboração da comunidade científica nacional, a } \\
\text { sanção da Lei n.o } 11.794, \text { que trata do uso científico dos animais, } \\
\text { representou um avanço inestimável, a despeito da presença de alguns } \\
\text { pontos que, eventualmente, merecessem outro tipo de tratamento. }\end{array}$ \\
\hline
\end{tabular}

Fonte: Porto TNRS, et al., 2020. 
Os primeiros cientistas postulavam que os animais eram seres desprovidos de almas, sendo assim, jamais poderiam sentir dor. Essa informação permeou o meio científico por muitos anos.

Depois já se pensava na amabilidade desses seres e foi com esse pensamento filosófico que os cientistas buscaram novas maneiras para a utilização de animais em procedimentos científicos. Dessa forma a própria ciência vem desenvolvendo, a cada dia, tecnologias inovadoras que buscam substituir o uso de animais por programas de computadores. A utilização de animais como modelos experimentais deve ser supervisionada por profissionais competentes, sendo de forma humanitária e minimizando ao máximo possível a dor e o sofrimento (FISCHER ML, et al., 2016).

O desenvolvimento de vacinas para a poliomielite foi testado inicialmente em modelos animais. Algumas técnicas também são essenciais a utilização dos modelos animais, como exemplo, os procedimentos cirúrgicos, em especial, transplantes de órgãos. Vale ressaltar ainda que estudos com animais possibilitaram conhecer o funcionamento dos sistemas e órgãos devido a semelhança fisiológicas existentes entre os seres humanos e algumas espécies de animais. Muitas informações científicas são frutos da utilização dos animais como modelos, tanto no campo da imunologia, da fisiologia, quanto da cura do câncer, Acquired immune deficiency syndrome (SIDA), Alzheimer, além de testes biomédicos (YUNTA ER, et al., 2007 e SHELLEY CW, 2010).

$\mathrm{O}$ argumento desses pesquisadores tem como referência a analogia entre os animais e entendem que se deve considerar o poder preditivo do estudo. Se a fisiologia animal não apresentasse semelhança aos sereshumanos, somente assim, tais modelos não teriam validade. Como ocorrem semelhanças torna-se válido os diferentes modelos experimentais (SHELLEY CW, 2010). A utilização de animal é extremamente necessária pois não há recursos tecnológicos suficientemente eficientes para substituí-los (FRANCO AL, et al., 2014).

Pesquisa realizada por Fischer ML, et al. (2016), demonstrou que a maioria dos acadêmicos em centros universitários afirmou que há carência de debates que discutem a utilização de animais em pesquisas. No entanto, os das áreas biológicas apresentaram-se mais preocupados, questionando inclusive a substituição de animais não somente em pesquisas, mais também para outros fins como vestimenta, alimentação, trabalho, entretenimento e companhia. Outro ponto importante discutido foi que a utilização dos animais em pesquisa é um mal necessário, no entanto, deve existir rigoroso método de controle, seja promovendo redução no uso, aplicação de penalidades á aqueles que fogem dos métodos legais, controlar práticas como a compra e a venda ilegal ou ainda implementação de comitê de ética mais eficiente.

Em estudo realizado por Diniz R, et al. (2006), sobre como alunos da graduação se sentiam em relação ao uso de animais nas práticas. Cerca de $50 \%$ dos acadêmicos de medicina disseram ter "sentimentos negativos" ao uso de animais nas aulas práticas, com uma grande variação entre as mulheres $(60,8 \%)$ e os homens (30,6\%). Sentimentos como: angústia, nervosismo e tristeza foram relatados com certa frequência.

Resultado semelhante foi encontrado no estudo de Tréz TA (2015) onde uma variação também foi descrita com relação ao sentimento de desconforto entre os gêneros. A frequência desse incômodo entre os alunos que participaram de aulas práticas com modelos animais foi de $65 \%$ entre as mulheres e $48 \%$ entre os homens. No que diz respeito a relevância do desconforto, consideraram como relevante e/ou muito relevante $(27 \%)$ dos homens e $(46 \%)$ das mulheres.

Gomes GM (2009) em sua pesquisa que analisou o desconforto entre estudantes de ciências biológicas e da saúde, cerca de $(41 \%)$ deles relataram ter sentido algum tipo de incômodo moral ou físico durante as práticas com modelos animais, porém com uma considerável variação entre os cursos (69\%) no curso de biologia e (30\%) no curso de medicina. No estudo de Zheng M, et al. (2017), com o objetivo de observar a rapidez da ação da insulina, o modelo animal utilizado foi induzido através da administração da droga via intraperitoneal, para a indução de camundongos à diabetes, porém respeitando a ética que rege este tipo de experimento e visando o bem estar animal. Para Souza IMA (2017) a utilização do modelo animal, em especial de roedores é uma prática consolidada entre as pesquisas, que objetivam caracterizar os processos biológicos e/ou testar tratamentos e medicamentos, antes de confirmar se os resultados se aplicam aos humanos. $O$ 
uso de animais se baseia na similaridade genética entre humanos e os roedores. Os corpos dos modelos animais são vistos como substitutos dos humanos, porém não significa dizer que sejam apenas representações cognitivas, pois eles também são canais de ações e práticas que estabelecem questões científicas e mostram quais perguntas podem ter respostas.

Ito $S$ et al. (2017) em sua pesquisa mostra o modelo animal como um importante instrumento de pesquisa, visto que alguns animais apresentam semelhanças morfológicas com os seres humanos. Em seu estudo relatou que a próstata canina possui semelhança morfológica e que desenvolve lesões prostáticas cancerígenas semelhante a do homem. Desta forma, o cão é um excelente exemplo de modelo espontâneo, pois desenvolve as alterações genéticas prostáticas e espontâneas, o que o torna um importante modelo animal na compreensão destas doenças.

O emprego de diversas técnicas, associado à utilização de várias espécies de animais são essenciais para conhecer e entender os mecanismos biológicos seja dos seres humanos quanto de outras espécies. Muitos animais são utilizados como modelos nas pesquisas experimentais, sendo por ano cerca de 15 milhões nos Estados Unidos. No Brasil, no entanto, o número é desconhecido, ainda assim, não é tão significativo se comparado aos outros países (MENDES MPG e SOUZA CAJ, 2017).

Doorbar J (2016) em sua pesquisa sobre papilomavírus humano (HPV) relata que apesar de ter a disposição modelos animais in vitro para a pesquisa da doença, e suas aplicações no estudo do HPV, para o estudo sobre o papilomavírus é necessário o uso de modelos in vivo para ser totalmente compreendido. $O$ autor relata também que existe na literatura muitos estudos voltados para os papilomavírus animais, como 0 do coelho e recentemente, papilomavírus do rato.

A área veterinária, uma alternativa para o fim da utilização de animais, são os modelos artificiais. São modelos de cães e gatos, de vários tamanhos, simulando a respiração e demais parâmetros fisiológicos. Muitos estudiosos combatem este tipo de utilização, com o argumento de que os modelos não reproduzem totalmente os aspectos bem como as condições encontradas no uso de um animal de verdade. Vale ressaltar que o uso de bonecos e de modelos artificiais já é prática comum na medicina e também em treinamentos de primeiros socorros, utilizados na simulação de diversos tipos de queimaduras, a forma correta de respiração artificial e outros (MENDES MPG e SOUZA CAJ, 2017).

Pode-se observar que a questão do sofrimento animal aparece como a principal razão do incômodo. Duas explicações podem ser estabelecidas a partir dessa questão. A primeira é a inadequação no manuseio e condução da experiência, podendo ser pelo despreparo profissional, ou imprevisto durante a execução dela, o que configura situação de maus-tratos. A segunda é que há uma percepção sensível ou crítica por parte do acadêmico com relação a definição de sofrimento animal (TREZ TA, 2015).

Existem muitos movimentos espalhados por várias partes do mundo em busca de alternativas para minimizar o uso de animais como modelos experimentais. Essas inquietações buscam substituir os animais por recursos tecnológicos inovadores, como teste in vitro entre eles o mais comum é a cultura celular. Em países desenvolvidos como Estados Unidos, Canadá, Inglaterra e países ocidentais como Índia e Japão, o uso de modelos computadorizados e simuladores fisiológicos são muitos utilizados (PINHEIRO LM, et al., 2007).

Técnicas cirúrgicas importantes como as microvasculares estão sendo realizadas com placenta humana. Simulações cirúrgicas, utilizando manequim de baixo custo e de fácil manipulação, são muito usadas em práticas complexas, como as do trato gastrointestinal.

A discussão não é referenciada apenas no sentimentalismo considerando aos animais como indefesos. É algo muito mais complexo, luta-se contra essa metodologia que é descrita como ultrapassada por muitos pesquisadores (LOPES CF, 2004).

A utilização de animais como modelos experimentais em pesquisas e em aulas práticas, principalmente na área da saúde, é uma realização bastante antiga assim, surgiu nos últimos anos à necessidade de criar mecanismos que normatizassem o uso dos animais em experimentos no Brasil. Essa regulamentação busca 
acima de tudo eliminar maus-tratos, atos de crueldade a esses animais, e ainda, promover melhorias nos aspectos metodológicos e garantir a ética nos estudos científicos (BRASIL, 2008).

Os recursos alternativos mais utilizados pelos pesquisadores de uma universidade brasileira foram a cultura celular e tissular, principalmente devido a facilidade de execução do mesmo, porém, foram citados outros modelos como a utilização da placenta, programas de informática, pesquisas clínicas e epidemiológicas (PINHEIRO LM, et al., 2007).

Já no estudo publicado por Oliveira FCS, et al. (2009), afirmou existir modelos farmacológicos e quânticos que avaliam a farmacocinética de drogas no organismo e técnicas que demonstram a ação das doenças no organismo humano, como a necropsias e biopsias. Alguns centros universitários possuem simulações computadorizadas que são usados no ensino das ciências biomédicas e modelos matemáticos que analisam os processos que ocorrem nos organismos vivos.

No Brasil e em outros países em desenvolvimento, movimentos pro alternativos para o uso de animais como modelos experimentais, estão sendo polarizados em duas vertentes: um defende a utilização de animais em pesquisas somente mediante legislação específica e o controle efetivo de comitês de ética, e o outro defende a abolição total de experimentos usando modelos in vivo (PINHEIRO LM, et al., 2007).

Diante dessa dualidade, a comunidade científica brasileira espera por uma resolução que defina de fato a conduta dos experimentos no país, que o Brasil possa criar norma federal abrangente e realista, com orientações claras e reguladoras, com menos características sancionadoras e que contemple a comunidade científica e ainda mais é de suma relevância que os pesquisadores tenham conhecimentos de vários métodos para realização de pesquisa, bem como conhecer, as limitações de cada modelo (MARQUES RG, et al., 2005).

Assim, evidenciou nas pesquisas que a maior dificuldade para a utilização de meios alternativos é a escassez de recursos financeiros nas universidades brasileiras e a falta de credibilidade dos resultados obtidos quando comparados àqueles realizados em modelos in vivo (PINHEIRO LM, et al., 2007).

\section{CONSIDERAÇÕES FINAIS}

O estudo demonstrou que a utilização de animais como modelo experimental está passando por processo de transformação tanto nos aspectos legais como metodológicos. Almeja-se que o estudo subsidie ações de promoção de estratégias que ajudem na transformação desta prática, visando o bem estar animal e o aprendizado dos estudantes, assim como o desenvolvimento de outros estudos sobre o tema. A limitação principal do estudo foi a escassez de estudos originais voltados para o tema.

\section{REFERÊNCIAS}

1. BRASIL. Ministério da Saúde. Lei oㅜ 11.794, de 8 de outubro de 2008. Regulamenta o inciso VII do parágrafo 1ํ do artigo 225 da Constituição Federal, estabelecendo procedimentos para o uso científico de animais, 2008.

2. CHUNG F. Thalidomide pharmacokinetics and metabolite formation in mice, rabbits, and multiple myeloma patients. Clinical Cancer Research, 2004; 10(17): 5949-5959.

3. DINIZ R, et al. Animais em aulas práticas: podemos substituí-los com a mesma qualidade de ensino? Revista Brasileira de Educação Médica, 2006; 30(2): 31-41.

4. DOORBAR J. Model systems of human papillomavirus-associated disease. The Journal Of Pathology, 2015; 2(238): 166-179.

5. FISCHER ML, et al. Bioética ambiental: concepção de estudantes universitários sobre o uso de animais para consumo, trabalho, entretenimento e companhia. Ciência Educação. 2016; 22(1): 163-182.

6. FISCHER ML, et al. Concepção, implementação e consolidação do Comitê de Ética no uso de Animais da PUCPR. Estudos de Biologia Ambiente e Diversidade. 2014; 36(1): 23-45.

7. FRANCO AL, et al. Pesquisas em animais: uma reflexão bioética. Acta Bioethica. 2014; 20(2): 247-253.

8. GOMES GM. A percepção de estudantes de ciências biológicas e da saúde sobre o uso de animais vivos em aulas práticas na Universidade do Vale do Itajaí (Univali-SC). Monografia (Graduação) - Universidade do Vale do Itajaí, Itajaí. 2009. 
9. GREIF S, et al. A Verdadeira Face da Experimentação Animal - a sua saúde em perigo. Rio de Janeiro: Editora Falabicho. 2000.

10. GREIF S, et al. Alternativas ao Uso de Animais Vivos na Educação - pela ciência responsável. São Paulo: Instituto Nina Rosa. 2003.

11. GUIMARÃES MV, et al. Utilização de animais em pesquisas: breve revisão da legislação no Brasil. Revista bioética. $2016 ; 24(2): 217-24$.

12. HAGELIN J, et al. An overview of surveys on how people view animal experimentation: Some factors that may influence the outcome. Public Understanding of Science. 2003; 12(1): 67-81.

13. ITO S, et al. Regulation of tight-junction integrity by insulin in an in vitro model of human blood-brain barrier. Journal Of Pharmaceutical Sciences, 2017; 1(17): 1-35.

14. KNIGHT S, et al. Science versus human welfare Understanding attitudes towards animal use. Journal of Social Issues. 2009; 65(1): 463-483.

15. MAGALHÃES MO, et al. Alternativas ao uso de animais como recurso didático. Ciências Veterinárias e Zoologia da UNIPAR. 2006; 9(2): 147-54.

16. MARQUES RG, et al. Rumo à regulamentação da utilização de animais no ensino e na pesquisa científica no Brasil. Acta Cirúrgica Brasileira. 2005; 20(3): 262-267.

17. MENDES MPG, SOUZA CAJ. Aplicação de modelos animais na pesquisa biomédica experimental. Revista de Saúde da Faciplac. 2017; 4(2): 41-58.

18. LEVAI LFO. O direito à escusa de consciência na experimentação animal. Pensata Animal, 2010; $2(1): 56-88$.

19. MARQUES RG, et al. Brazilian law for scientific use of animals. Acta Cirúrgica Brasileira. 2009; 24(1): 25-35.

20. MARQUES RG, et al. Rumo à regulamentação da utilização de animais no ensino e na pesquisa científica no Brasil. Acta Cirúrgica Brasileira. 2005; 20(3): 262-267.

21. MENEZES HS. Ética e pesquisa em animais. Rev Amrigs. 2002; 46(3): 105-108.

22. OLIVEIRA FCS, et al. Experimentação animal: por um tratamento ético e pelo Biodireito. In: XVIII Encontro Nacional CONPEDI, 2009, Maringá.

23. PINHEIRO LM, et al. O conhecimento de recursos alternativos em pesquisa com animais de laboratório. Estudos de Biologia. 2007; 29(67): 157-163.

24. PRESGRAVE OAF, et al. A Proposal to establish a Brazilian Center for Validation of Alternative Methods (BraCVAM). Special, 2010; 47(1): 221-241.

25. REZENDE AH, et al. Experimentação animal: ética e legislação brasileira. Revista de Nutrição. 2008; 21(2): $237-42$.

26. RODRIGUES GS, et al. Estudo exploratório acerca da utilização de métodos alternativos em substituição aos animais não humanos. Revista bioética. 2011; 19(2): 577-596.

27. SCHATZMA YR, et al. As interfaces da bioética nas pesquisas com seres humanos e animais com a biossegurança. Ciência Veterinária nos Trópicos. 2008; 11(2): 130-134.

28. SHELLEY CW. test animals to treat humans? On the validity of animal models. Studies in History and Philosophy of Biological and Biomedical Sciences. 2010; 41(3): 292-299.

29. SILVA TTA. Crítica à herança mecanicista de utilização animal: em busca de métodos alternativos. Anais do XVII Encontro Preparatório para o Congresso Nacional do Conpedi Florianópolis: Fundação Boiteux; 2008; 495p.

30. SOUZA IMA. Corpos comensuráveis: produção de modelos animais nas ciências biomédicas. Horizontes Antropológicos, 2017; 23(48): 275-302.

31. TRÉZ TA. A caracterização do uso de animais no ensino a partir da percepção de estudantes de ciências biológicas e da saúde. História, Ciências, Saúde- Manguinhos. 2015; 22(3): 863-880.

32. TINOCO IAP, et al. Reflexões éticas sobre a vivissecção no Brasil. Anais do XIX Encontro Nacional do Conpedi. Florianópolis: Fundação Boiteux; 2010; 6477p.

33. YUNTA ER. Ética de la investigación en modelos animales de enfermedades humanas. Acta Bioethica. 2007; 13(1): 23-35.

34. ZHENG M, et al. Folic Acid Reduces Tau Phosphorylation by Regulating PP2A Methylation in StreptozotocinInduced Diabetic Mice. Int. J. Mol. Sci, 2017; 18(861): 1-13. 